
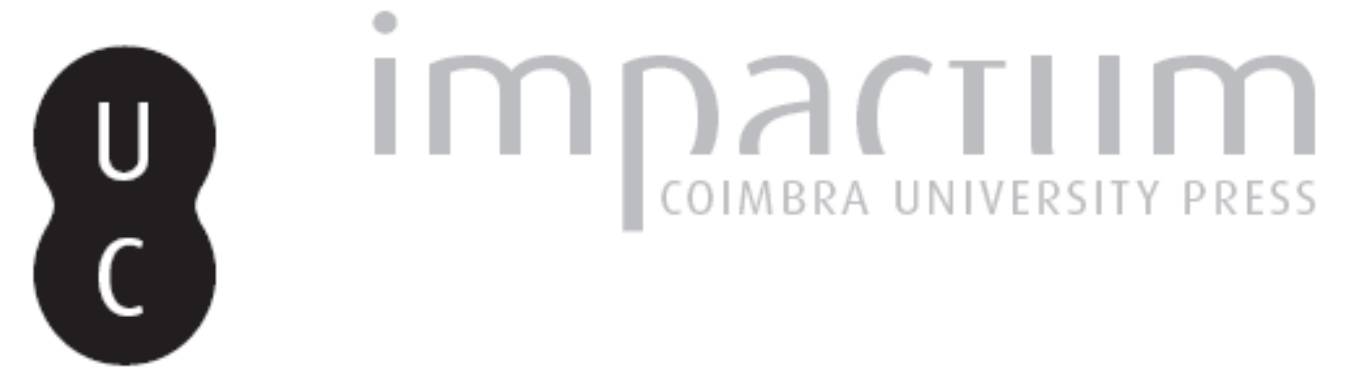

Tradução e restituição: (algumas notas reflexivas de um tradutor não-profissional)

Autor(es): $\quad$ Vasconcelos, José Manuel de

Publicado por: Imprensa da Universidade de Coimbra

URL persistente:

URI:http://hdl.handle.net/10316.2/42651

DOI:

DOI:https://doi.org/10.14195/0870-8584_2_17

Accessed : $\quad$ 26-Apr-2023 10:03:22

A navegação consulta e descarregamento dos títulos inseridos nas Bibliotecas Digitais UC Digitalis, UC Pombalina e UC Impactum, pressupõem a aceitação plena e sem reservas dos Termos e Condições de Uso destas Bibliotecas Digitais, disponíveis em https://digitalis.uc.pt/pt-pt/termos.

Conforme exposto nos referidos Termos e Condições de Uso, o descarregamento de títulos de acesso restrito requer uma licença válida de autorização devendo o utilizador aceder ao(s) documento(s) a partir de um endereço de IP da instituição detentora da supramencionada licença.

Ao utilizador é apenas permitido o descarregamento para uso pessoal, pelo que o emprego do(s) título(s) descarregado(s) para outro fim, designadamente comercial, carece de autorização do respetivo autor ou editor da obra.

Na medida em que todas as obras da UC Digitalis se encontram protegidas pelo Código do Direito de Autor e Direitos Conexos e demais legislação aplicável, toda a cópia, parcial ou total, deste documento, nos casos em que é legalmente admitida, deverá conter ou fazer-se acompanhar por este aviso. 


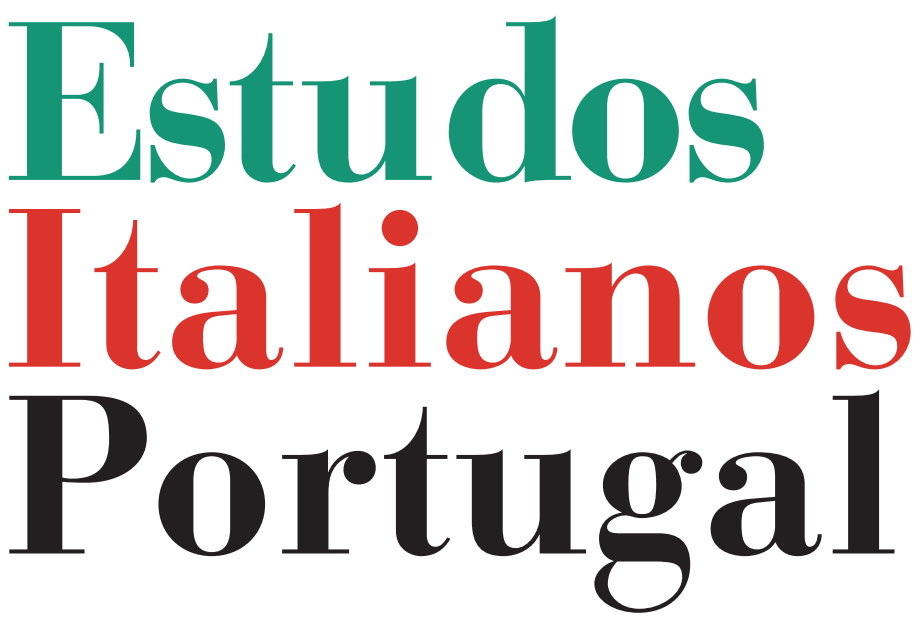

Instituto

Italiano

de Cultura

de Lisboa

Nova Série

$\mathbf{N}^{\mathbf{0}} 2$ 


\title{
TRADUÇÃO E RESTITUIÇÃO \\ (ALGUMAS NOTAS REFLEXIVAS \\ DE UM TRADUTOR NÃO-PROFISSIONAL)
}

\author{
José Manuel de Vasconcelos
}

NÃo SERÁ NENHUMA NOVIDADE afirmar que, com a tradução, se procura interpelar e acolher o Outro naquilo que o torna específico e diferente, no seio de um sistema cultural com características próprias e consciente de si. Desde Schleiermacher e do seu hoje muito estudado Über die verschiedenen Methoden des Übersetzens, de 1813, que identidade e alteridade são categorias fundamentais para se equacionar a acção tradutiva, simbolizada na notação $\mathrm{T} 1 \rightarrow \mathrm{T} 2^{1}$. Esta ideia, com contornos de emboscada amigável, foi posteriormente reforçada pelos estudos, também hoje bem conhecidos, de Humboldt, Benjamin e Ortega y Gasset ${ }^{2}$. Para estes vários

* José Manuel de Vasconcelos nasceu em Lisboa. Exerce advocacia. Poeta, ensaísta e tradutor, traduziu, entre outros, os futuristas italianos, Federico Garcia Lorca, Severo Sarduy, Italo Calvino, Bruno Munari, Eugenio Montale, encontrando-se a preparar uma antologia de Saba. É administrador da Fundação Mário Botas e membro da direcção da Associação Portuguesa de Escritores. Faz parte do conselho de redacção da revista $O$ Escritor e, com o poeta António Osório, organiza a revista Foro das Letras, da Associação Portuguesa de Escritores Juristas.

1 Texto 1 e Texto 2. Podemos escolher, entre várias outras possíveis, a terminologia texto de partida/texto de chegada.

2 Nem todos porém pensam assim. A título de exemplo de um entendimento que mais do que procurar essa integração, prefere pôr a tónica na alteridade e na viagem quase sem retorno a um outro espaço que é alheio à cultura do texto de chegada, falarei de Vladímir Nabokov. Para o romancista e ensaísta de ori- 
pensadores, pese embora os aspectos diversos das suas concepções acerca da tradução, parece poder concluir-se que todos a encaram como um conjunto de processos através dos quais se visa um acolhimento e uma integração (Schleiermacher usa mesmo a palavra Gastfreiheit, que se poderá traduzir por hospitalidade, para transmitir a ideia da permanência do tradutor no texto de partida, e deste texto de partida, no ambiente cultural e linguístico no qual vai ser recriado) e que pressupõe previamente uma viagem, o estabelecimento de pontes com o texto a traduzir, e com a cultura da qual ele é (também, embora não só) expressão. Ou seja, regista-se aqui o impulso de transcendência que a tradução começa por ser. Schleiermacher, pilar do pensamento hermenêutico moderno, põe a tónica das suas concepções na compreensão, demarcando-se dos meros processos de exegese, assentes, na maior parte dos casos, no estabelecimento de regras predominantemente linguísticas de abordagem dos textos, com as quais se procurava explicitar o texto-fonte do ponto de vista da sua inteligibilidade imediata. O que o filósofo e teólogo alemão propõe, é ultrapassar a abordagem apenas explicativa

gem russa, o texto de chegada deve dar conta da componente de estranheza do texto de partida, mesmo à custa da sua inteligibilidade, procurando-se consolidar as fracturas que, para o leitor do texto traduzido, vierem a resultar dessa estranheza, através de notas, com a abundância e a extensão que se mostrarem necessárias. Este entendimento "literalista” preocupa-se, antes de tudo, com o sentido preciso das palavras no texto original, mais do que com a criação de um texto "duplo" que dê conta do contexto cultural em que se insere a obra a traduzir, e do qual ela nasce, bem como da complexidade do universo poético do seu autor, e tem na prática tradutiva esse exemplo notável pela sua singularidade, que é a tradução do Eugene Onegin de Pushkin, feita pelo próprio Nabokov, em que o texto traduzido para inglês ocupa, na edição de que disponho, cerca de duzentas páginas e os comentários do tradutor praticamente todo um volume com mais de quatrocentas páginas. Cf. Eugene Onegin, A Novel in Verse by Aleksandr Pushkin, translated from the Russian, with a Commentary, by Vladimir Nabokov, paperback edition in two volumes, Bollingen Series LXXII, Princeton University Press, 1990. 
do texto, substituindo-a pela compreensão, isto é, por uma busca reflexiva e auto-reflexiva do próprio processo de criação que lhe está subjacente, pela perscrutação de um verdadeiro e próprio pensamento (e das suas margens), que o texto pressupõe e co-involve. Embora sejam manifestos os traços epocais deste pensamento, imbuído de Romantismo, não deixa o mesmo de ser um decisivo contributo crítico para a separação fundamental entre simples explicação e compreensão, o que, aplicado à problemática da tradução, deixa claro que o tradutor não pode ser um simples explicitador de significados, dados através de equivalentes linguísticos, transmitindo apenas aquilo a que Derrida chamou o "sentido comunicável" do texto, devendo a sua actividade ir mais longe, manifestando uma apropriação de algo que se apresenta, a princípio, como um horizonte de estranheza, uma transcendência, que a pouco e pouco se conquista, se entranha e se difunde no texto de chegada, que terá de ser construído ou recriado como um todo coerente onde, para além de texto em sentido linguístico, se deverá assegurar que fulja um pensamento e uma cultura. Esta dimensão cultural da tradução, a que Heidegger e Gadamer deram tanta atenção, é pois fundamental, e exige do tradutor um conjunto de qualidades e de conhecimentos apreciáveis, sem os quais, por melhor que a tradução seja do ponto de vista da sua fidelidade linguística imediata, não nos poderá garantir que estejamos perante um trabalho apreciável. De facto, casos há em que o tradutor, tendo um conhecimento profundo da língua e sendo a sua tradução impecável do ponto de vista das equivalências linguísticas, pode ficar aquém de outra, feita por alguém que não tem da língua de partida um domínio tão seguro, mas sabe dar na tradução um equivalente que, não atraiçoando a "letra" do texto, sabe ir mais longe, criando na língua alvo uma "imagem" do estilo do autor e das raízes desse estilo, que provoquem no leitor da tradução impressões muito semelhantes àquelas que o texto original provo- 
cou nos seus leitores ${ }^{3}$. O que acabo de dizer, pode tornar-se bem mais evidente quando se trata de tradução de poesia.

Uma outra questão curiosa é a do papel da emotividade do tradutor no seu trabalho. Com efeito, sentimentos, estados de espírito, intromissão de afectos podem tomar conta do tradutor durante o processo de tradução, o que, certamente, condicionará o resultado obtido. Deixando de lado o que João Barrento designou como "tradução de serviço" e fixando-me apenas na tradução literária, consciente de ser um acto de recriação, destacaria duas possíveis atitudes emotivas, genéricas, do tradutor face ao texto que se propõe traduzir: a) a adesão ao texto e ao autor, nos vários graus que pode ter uma relação amorosa (desde o interesse mais imediato fundado numa adesão motivada pela simples simpatia, até à perturbada e envolvente paixão, capaz dos mais desvairados excessos); b) a estranheza, a dissemelhança incómoda, a antipatia mesmo. Estas duas atitudes não implicam que o tradutor, envolvido em qualquer delas, não possa fazer um excelente trabalho, pois certamente terá o controlo racional das suas impressões e emoções e será capaz de atravessar com serenidade as brumas que lhe poderiam toldar a sageza e aportar com êxito no cais dos seus objectivos. E isto, mesmo no caso de falta de empatia com o texto a traduzir, mesmo quando o texto alvo possa provocar até talvez uma certa irritação, desde que se reconheça nele qualidade literária e se possa encará-lo como um desa-

3 Um exemplo curioso e extremo encontra-se em duas traduções, uma francesa e outra brasileira, do Pygmalion de Georg Bernard Shaw, nas quais, os respectivos tradutores, para darem aos leitores uma ideia mais viva da evolução por que passa a personagem feminina principal no seu modo de falar, sob a orientação do professor de linguística, transferem a acção respectivamente para as margens do Sena e para o Rio de Janeiro, chegando mesmo o tradutor brasileiro a mudar os próprios nomes das personagens da peça para nomes brasileiros, de modo a melhor garantir a verosimilhança das soluções idiomáticas adoptadas. 
fio ${ }^{4}$. Mesmo neste caso, a tradução continuará a fazer-se certamente por prazer, podendo até resultar de um esforço de aproximação do texto, para uma mais penetrante compreensão. De facto, sabemos que são geralmente coisas bem diferentes, a leitura normal, mesmo que bem atenta e crítica (aquilo a que se poderia chamar a leitura "de lápis na mão") e a microleitura que antecede, que conduz, e que envolve a recriação tradutiva, na qual, para além do sentido geral e mais imediato, se procura na dilucidação das malhas linguísticas do texto, por vezes bem apertadas e até enganadoras, um equivalente eficaz na língua de chegada. Só isso, em conjunto com o prazer da tradução voluntária, explicarão o facto de muitos escritores fazerem traduções, às vezes sem sequer existir o intuito da sua publicação, outras vezes publicando-as sob pseudónimo. Em certas ocasiões, só reescrevendo o texto na sua língua de leitor e de escritor se dá realmente conta do que se tem pela frente e se desce

${ }^{4}$ Imagino que um tradutor competente não deixará de fazer um excelente trabalho de tradução de obras de autores como, por exemplo, Louis-Ferdinand Céline, só por não concordar com os pressupostos ideológicos e políticos do seu pensamento, e com a correspondente expressão literária dos mesmos. Certamente isso não aconteceria, pois não deixará de se reconhecer no autor de Rigodon um dos maiores escritores franceses de sempre. Já o mesmo se não poderá dizer, quando nos afasta do texto a traduzir um sentimento de desinteresse ou mesmo de repulsa, por se tratar de pseudo literatura com intuitos meramente comerciais. A este propósito, gostaria de contar aqui a história de um amigo, tradutor profissional que, confrontado com péssimos romances, piegas, sensacionalistas e de um kitsch demolidor da mais complacente paciência, dava consigo a recriar as frases de uma tal maneira, procurando conferir-lhes um mínimo de dignidade literária, que, por vezes, algumas páginas logravam um halo de interesse, insuspeitado no texto original. Claro que se tratava não de um acto de tradução, mas de uma tentativa de salvação. Concluo esta história verdadeira, revelando que o Editor, ao aperceber-se do facto de que o tradutor estava a destruir ao nível do microtexto os pressupostos que tinham dado aos livros o seu carácter de best-sellers, procurando apelar para um resto de inteligência e de sensibilidade dos leitores, rapidamente o dispensou de fazer mais traduções para a sua Editora. 
vertiginosamente aos mais perturbantes abismos do texto. Pessoalmente, quando gosto muito de um poema, tenho quase sempre vontade de o traduzir, e sinto que o processo da sua leitura e da sua apropriação só fica, não direi completo, mas relativamente estabilizado, quando chego ao fim da sua tradução. Estas traduções nascem da admiração, da afinidade, mas também da estranheza que se sente pelo que nos é alheio e é diferente, ou pelo que é, a um tempo, tão longínquo e tão próximo, que caminha a nosso lado, das mais diversas maneiras, para sempre. Talvez resida aí o interesse e o gosto pela tradução dos clássicos, da confrontação de atitudes que da sua leitura quase sempre nasce, fruto da distância temporal e, mais do que em qualquer outro caso, do sentimento de alteridade que essa distância provoca. Para recorrer a uma expressão da teoria musical, parece haver neste caso como que um "contraponto imitativo", isto porque, a voz do tradutor modela a sua frase à semelhança da frase criada pela voz que o precede (a do autor traduzido).

Marguerite Yourcenar referia-se a este gosto pelos clássicos e à aventura de tradução que daí por vezes resulta, comparando-a com a comum revisitação das grandes telas feita por diversos artistas plásticos ao longo dos tempos, para melhor "se deixarem penetrar pelos segredos da sua arte" 5

Não obstante as dificuldades específicas que qualquer tradução literária apresenta, quase sempre agravadas quando se trata de poesia, as semelhanças estruturais entre a língua de partida e a língua de chegada podem minimizar, em certos casos, essas dificuldades. Ainda há dias, José Bento, grande tradutor e divulgador das literaturas em língua espanhola, quando o felicitei pelos prémios que recentemente lhe foram atribuídos, me dizia que, no seu longo trabalho de tradutor, tinha tido duas grandes ajudas: por um lado, alguns editores

Marguerite Yourcenar, prefácio a La Couronne et la Lyre (poèmes traduits du grec), Paris, Gallimard, 1988, p. 9. 
de grande sensibilidade e nível intelectual; por outro, o facto de traduzir da língua espanhola. A verdade desta afirmação não tira de modo nenhum o mérito a quem traduziu textos tão vastos e dificeis como o D. Quijote, e autores da complexidade de Lorca, Quevedo e Vallejo, por exemplo, mas não há dúvida de que, traduzindo do espanhol para o português, se podem mais fácil e correntemente manter rimas, jogos de palavras, efeitos fonéticos e rítmicos (aquilo a que Pound chamava melopoeia) ${ }^{6}$, do que quando se traduz de línguas mais afastadas da nossa, e até com outras raízes e de outras famílias (pensemos em traduções do russo, do turco, do árabe, do húngaro, do chinês e do japonês, por exemplo) ${ }^{7}$,

${ }^{6}$ Palavra com a qual, Ezra Pound, no seu $A B C$ of Reading, a propósito da poesia provençal, se referia ao ajustamento do motz el son à melodia, ou seja, à aproximação da poesia à música (quer os versos fossem cantados, salmodiados ou falados) como maneira de a poesia não se atrofiar.

7 A propósito do japonês e do turco, não posso deixar de sentir estranheza que se continue a traduzir e a publicar traduções em Portugal (sem qualquer desprimor para o trabalho dos respectivos tradutores) que não sejam feitas a partir do original, facto hoje completamente impensável em países da Comunidade Europeia, como a Espanha, a França, a Itália ou a Inglaterra), o que, também no campo da tradução, como em tantos outros, nos deixa à porta da Europa (e nem sequer à porta principal, e sim à porta de serviço...!). Ainda recentemente, verifiquei que os romances do japonês Haruki Murakami são incompreensivelmente traduzidos do inglês, bem como os romances do Nobel de 2006, Orhan Pamuk, acabados de sair também em traduções "de segunda mão", o que implica o alinhamento nas opções de tradução já feitas, e que podem em alguns casos ser bastante discutíveis, perdendo-se assim toda a dignidade tradutiva pela inevitável submissão a um Tradutor-Sombra e a um texto que, sendo de chegada, se apresenta enganadoramente como texto de partida. Claro que esta triste situação tem as suas explicações, sendo uma delas, certamente, o facto de se pagar tão mal aos tradutores profissionais que, quem sabe línguas menos vulgares, não está para perder tempo a fazer traduções e quem gostaria de estudar certas línguas para o fazer, perde facilmente a vontade, se precisar de ganhar a vida a fazer traduções. Ficamos então dependentes de certos tradutores, uns profissionais outros não, que, por gosto pessoal e paixão pela divulgação da literatura e da cultura, se empenham na tradução e/ou divulgação de obras, traduzindo-as directamente das línguas originais. A título exemplificativo, e em 
para além de que, no caso das línguas próximas, o leitor comum tem uma possibilidade de mais estreito controle do trabalho tradutivo (particularmente em edições bilingues de poesia que, felizmente, se estão a tornar regra no exíguo, mas excelente, mundo editorial português da poesia). Com a língua italiana, tudo se passa de forma muito semelhante ao castelhano, o que pode conferir, quer à tradução de italiano para português, quer à de português para italiano, aspectos interessantes, alguns dos quais passarei a referir.

Apercebi-me bem disso, ao traduzir poemas de Eugenio Montale e de Umberto Saba. Tenho de confessar, retomando o que acima disse sobre essa espécie de dialéctica da simpatia-antipatia e até do amor-ódio que por vezes acomete o tradutor, que o envolvimento com a poesia de Montale foi para mim uma verdadeira paixão. À medida que o estudava, que aprofundava o conhecimento da sua obra e da sua vida, descobria afinidades de pensamento, de sentimento, de gostos; deixava-me envolver por aquela tonalidade nostálgica de muitos dos seus poemas, aderia a seu cepticismo cavalheiresco, saboreava o seu humor discreto mas certeiro e, por vezes, senti que os seus versos iam perfumando até as minhas insónias. A minha curiosidade e interesse foram tão intensos que lamentei profundamente não ter podido conhecer pessoalmente o autor de La Farfalla di Dinard. Foi então, com enorme alegria, que me chegou às mãos, durante o trabalho de tradução, uma videocassete, que acompanhava o estudo biográfico sobre Montale de Enrico Testa ${ }^{8}$, com o registo do depoimento que o poeta deu à RAI, para a série

forma de modesta homenagem que lhes presto, citarei, para além do já referido José Bento, grande tradutor e divulgador de literaturas em língua espanhola, os nomes de João Barrento (para a divulgação das literaturas Alemã e Austríaca), Vasco Graça Moura e José Colaço Barreiros (para a da literatura italiana), Ernesto Rodrigues (para a da literatura húngara) e Gonçalo Vilas-Boas (para a divulgação das literaturas nórdicas).

${ }^{8}$ Enrico Testa, Montale, Einaudi Tascabili, Einaudi, Turim, 2000. 
"Poeti e scrittori italiani del Novecento", entremeado de imagens relativas à vida, à obra e às paisagens biográficas montalianas, onde pude ver e ouvir o poeta, por entre as nuvens de fumo dos seus inúmeros cigarros (hoje politicamente incorrectas) e aperceber-me da sua enorme capacidade para prender a atenção do espectador, e onde detectei aquele sentido de humor sóbrio e terapêutico que anda geralmente associado aos grandes cépticos. A verdade é que este pequeno filme de cerca de 40 minutos, mais do que os vários livros que li sobre o poeta, foi um dos elementos, estranhos à tradução propriamente dita, que mais me ajudou na recriação de uma atmosfera verdadeiramente montaliana durante a mesma.

Já com Saba, a relação tem sido diferente. O poeta do Canzoniere não teve uma vida fácil, não teve, desde logo, uma infầncia fácil. A sua origem judaica, no cadinho de culturas da Trieste do Império Austro-Húngaro, nos finais do século XIX, em que viveu, terá certamente condicionado o seu pendor neurótico. Os seus poemas são formalmente muito belos, mas a voz nervosa, frágil, tocada por um filigrânico lamento piegas, cheia de auto-comiseração, e auto-flagelante, cria, por vezes, uma incomodidade que não ajuda. Mas, falem-me de um amor no qual não exista por vezes irritação, ao qual se não possa aplicar a incontestável ambivalência contida no famoso poema de Catulo...!

Sabemos que, quer Montale, quer Saba, não são poetas fáceis de traduzir. No autor de Ossi di seppia, há que ultrapassar obstáculos que decorrem de uma linguagem que recorre com frequência a arcaísmos, à utilização de rimas muito discretas e por vezes anómalas, a aliterações e outros valores rítmicos, criando assincronias rítmicas e sintácticas que, transpostas para português, podem dar a ideia de uma má tradução. Há também um efeito estranho, resultante da abundância de anástrofes, e de uma forma muito pessoal de utilização da elipse. Tudo isto é responsável pelo clima de desolação, 
de solidão, pela voz metafísica e nostálgica, mas com uma firmeza que resulta do entrecruzar de um pensamento de alucinatórios microfulgores com a inércia de um colóquio existencial com as coisas mais simples e directas, que atravessa os poemas de Montale e que a tradução tem de "dar" em português. No segundo, é sobretudo a toada que é dificil de transpor, o estilo, feito de uma melodia sincopada, balbuciante, onde não são raros os efeitos luminosos e expressivos criados pelas rimas à volta de certas palavras-chave. Parece-me consideravelmente mais fácil traduzir poetas como Quasimodo, e sobretudo, Ungaretti. Deste último se poderia dizer até, com um certo exagero, que quase permite a tradução palavra a palavra.

Mas todas as dificuldades que se possam inventariar, a propósito da tradução da poesia italiana, não anulam o que disse sobre a maior tradutibilidade do texto que revela manifestas afinidades com o contexto linguístico e cultural do tradutor, reduzindo as diferenças e, consequentemente, provocando uma transfiguração na dialéctica alteridade-identidade. Ao reler uma antologia publicada em Itália em 1975, organizada por Carlo Vittorio Cattaneo, intitulada La Nuova Poesia Portoghese ${ }^{9}$, passando em revista os vários autores seleccionados, os textos em português e as traduções respectivas, verifiquei que certos autores (que julgo "mais perto da Itália”), como Ruy Belo e Pedro Tamen, resultam mais fáceis de traduzir para italiano, ou dito de outra forma, o tradutor não tem, para os traduzir, de procurar rebuscados equivalentes, não tem de transfigurar os versos, bastando-lhe assegurar uma controlada linearidade de correspondentes, sem sequer ter de alterar a ordem sintáctica. $\mathrm{O}$ mesmo não me parece que aconteça com outros poetas, em geral mais próximos da cultura francesa (Herberto Helder, Luiza Neto

9 La Nuova Poesia Portoghese, a cura di C.V. Cattaneo, Edizioni Abete, Roma, 1975. 
Jorge ou Nuno Júdice) ou anglo-saxónica (Gastão Cruz, Joaquim Manuel Magalhães, João Miguel Fernandes Jorge) ${ }^{10}$, para resultarem em italiano. Penso poder concluir-se daqui que, em certos casos, naturalmente raros, mas nem por isso destituídos de interesse teórico, a língua italiana, com os seus ritmos próprios, a sua música vocabular, com a sua sintaxe, pode até orientar, ainda que de forma inconsciente (como poderá suceder, de resto, com qualquer outra língua), o modo como irrompe a locução e como se organiza o discurso, pode influenciar a organização do verso e condicionar o enunciado poético em autores que com frequência lêem em italiano.

Na poesia portuguesa contemporânea, o caso mais notório (e notável) de afinidade cultural e linguística com a Itália é sem dúvida o caso de António Osório. A italianidade da sua poesia é uma característica inquestionável, reconhecida pelo próprio poeta. Filho de pai português e de mãe italiana, desde sempre a língua materna foi falada juntamente com o português no dia a dia do poeta. Para além disso, as primeiras leituras - que tão profundamente marcam -, tanto eram os clássicos portugueses do renascimento, nomeadamente

${ }_{10}$ Os primeiros, certamente mais fáceis de traduzir para francês, em virtude do facto de muito do pensar poético francês contemporâneo perpassar pelo que escreveram (veja-se como, por exemplo, as várias traduções de Nuno Júdice já existentes se poderão ler em francês sem qualquer estranheza ); os segundos, resultando mais facilmente em inglês. Outros casos de proximidade com o "colorido psicológico" dos idiomas anglo-saxónicos são os de Jorge de Sena, Rui Knopfly, Alberto de Lacerda ou Luís Amorim de Sousa, sendo o caso mais paradigmático o de Fernando Pessoa, pois não será certamente dificil de traduzir para inglês o que muitas vezes foi pensado e construído mentalmente nessa língua. As traduções inglesas de Pessoa dão-nos textos que poderiam passar por originais, se não soubéssemos quem é o seu autor. Veja-se, por exemplo, a tradução de O Marinheiro (The Marriner) feita por Richard Zénith, e incluída no livro Selected Prose of Fernando Pessoa, New York, Grove Press, 2001, em que há passagens que, em minha opinião, chegam a soar melhor em inglês (sem esquecer naturalmente o mérito do tradutor) do que em português. 
Camões (ele próprio tão tocado pela influência italiana), como Dante, entre outros, e os Gregos (com destaque para Homero), lido em voz alta, em traduções italianas. Osório teve assim uma educação caracterizada pelo bilinguismo, o que lhe permitiu também o acesso directo à literatura italiana, sem a mediação de outras línguas, mediação que, com raras excepções, foi regra em Portugal durante muitas décadas. É assim que já adulto vem a ler os grandes poetas italianos contemporâneos (Montale, Saba, Quasimodo, Ungaretti, Luzzi, Caproni). O resultado de tudo isto é uma poesia fortemente marcada por traços comuns aos vários poetas italianos que referi, mas, mais do que isso, um estilo que, formal e estruturalmente, muito deve à própria língua italiana. $\mathrm{Ou}-$ tros poetas portugueses apresentam influências italianas, mas elas misturam-se com outros apelos (franceses, espanhóis e até anglo-saxónicos), configurando influências compósitas. Mas, em casos em que a admiração pela cultura italiana é mais forte (pensemos em autores como Albano Martins, Pedro Tamen, Eugénio de Andrade, Vasco Graça Moura) a influência é mais evidente na temática, em certas alusões culturais, do que propriamente ao nível construtivo, como acontece com o autor de Décima Aurora ${ }^{11}$. O que acabo de referir levanta, no que respeita à tradução, uma questão curiosa, que consiste no facto de, na tradução para italiano, se perder, ou pelo menos se atenuar, o bilinguismo e a diver-

11 Osório tem sido também um leitor atento de espanhóis, franceses e brasileiros. E dessas leituras terão também vindo outras influências, só que essas a nível temático. Veja-se por exemplo, a influência da geração de 27 e, particularmente, da poesia "tauromáquica” espanhola (Lorca, Alberti, Bergamín), mas também a atitude perante o mundo animal, em que se substituiu o proteccionismo pela intercomunicação, e como o Paul Léautaud, desse livro ímpar que é Bestiaire, pode ter tido influência. De Cecília Meireles visitada, sobretudo através de uma tia do poeta, a poetisa Maria Valupi, creio que vem essa extraordinária qualidade, a que chamaria elementaridade, e que consiste em fazer grande poesia com poucas e simples palavras. 
sidade em que assenta todo o projecto tradutório. Esta aproximação linguística uniformizante, no texto fonte e no texto alvo, a que já se chamou hipertraduzibilidade ${ }^{12}$, é um caso extremo, e bem interessante, do que pode acontecer quando há manifestas semelhanças estruturais entre duas línguas, e se, por um lado, parece facilitar o trabalho do tradutor, por outro pode, em certos casos, dificultá-lo, precisamente em razão da inesperada apresentação do outro como um mesmo. A este propósito, João Bigotte Chorão refere que António Osório "Traduzido em italiano, é como que restituído à língua materna." ${ }^{13}$ Com efeito, o tradutor italiano de António Osório ${ }^{14}$ é desafiado por construções linguísticas que lhe permitem não ter em geral de se desviar muito das da língua alvo.

Ortega y Gasset, partindo da tese de que a língua pode por vezes ser um espartilho para o pensamento, podendo mesmo paralisá-lo ${ }^{15}$, e de que, além disso, as línguas separam os homens, entendia a tradução apenas como um dos caminhos possíveis para o original, que era visto como algo de irrepetível. Esta opinião afasta-se frontalmente da concepção da tradução como um duplo do texto original. Creio que o

12 Cf. Maria Alexandra Lopes, "Identidade versus alteridade: traduzindo William Boyd como provocação a Friedrich Schleiermacher", in Do Esplendor na Relva (elites e cultura comum de expressão inglesa), Direcção de Álvaro Pina, João Ferreira Duarte e Maria Helena Serôdio, Edições Cosmos/Associação Portuguesa de Estudos Anglo-Americanos, Lisboa, 2000, pp.377-382.

13 João Bigotte Chorão, "O visibile parlare de António Osório", in Brotéria, 213, vol.161, Agosto/Setembro de 2005.

${ }_{14}$ Com isto, não se desvaloriza a qualidade das traduções italianas de António Osório e as inúmeras dificuldades que tal tradução apresenta. Bem pelo contrário. Tais traduções são sem dúvida notáveis. O que se quis dizer, foi apenas que o tradutor, pelo ambiente a que pertence, a língua para a qual traduz, e a cultura em que se insere, beneficia à partida do facto de os textos a traduzir comungarem, em muito, desse ambiente e dessa língua e cultura.

${ }^{15}$ José Ortega y Gasset, Miseria y Esplendor de la Traducción, in Misión del Bibliotecario, Revista de Occidente, Madrid, 1962. 
problema se pode colocar, com vantagem, de uma outra maneira. É sabido que os tradutores trazem consigo o pecado original da imperfeição, o estigma do falso, do que é apenas cópia e, ainda por cima, geralmente imperfeita. Antoine Berman fala da "defectividade" do texto traduzido, e Georges Mounin acentua a ideia de culpabilidade, que anda geralmente associada ao tradutor, pelo facto de o seu trabalho ser sempre e inevitavelmente imperfeito. Culpabilidade pela mácula da "traição", pelo facto de que, por mais que se esforce, o texto traduzido é sempre inferior ao original, como o será qualquer cópia de um famoso quadro feito, ainda que autorizadamente, por um dos múltiplos pintores que povoam os grandes museus do mundo. Mas será verdade que qualquer tradução terá de ser sempre a irmã menor do irradiante texto que se pretende dar a conhecer num contexto que não é o da sua origem? Não creio que seja necessariamente assim. Parece-me possível, pela tradução inteligente, informada, vista como um trabalho de criação literária, conseguir-se um equivalente adequado do original, capaz de criar no leitor de chegada a mesma susceptibilidade impressiva que o texto original provoca quando lido, ou seja, um texto que pudesse ser apresentado como um texto original, sem aquelas escórias, aquelas marcas, aqueles pequenos "riscos", o esbotenado linguístico que resulta do transporte tradutivo. Poder ler-se, sem termos constantemente de pensar que estamos a ler uma tradução. Norman Shapiro põe a tónica nesse objectivo supremo da tradução, a que podemos chamar a transparência, e que resulta do facto de o tradutor agir fora de cena, se apagar mesmo, para que só o texto brilhe com uma luz que pareça a da sua luz original: "I see translation as the attempt to produce a text so transparent that it does not seem to be translated", escreve o tradutor norte-americano, colocando-se nos antípodas da ideia nabokoviana de tradução, em que o tradutor é rei e quase se sobrepõe ao autor, naquilo que se poderia chamar tradução de autor. Consciente embora de 
que um tal objectivo dificilmente será atingido - pois permanecem sempre no texto traduzido erros, imperfeições, descuidos, elementos de estranheza que lhe perturbam a fluidez, a aparência de autenticidade e toldam a limpidez e a coerência do esforço de apagamento do tradutor, conferindo-lhe um carácter estranho e quase criminal -, julgo que ele terá de colocar-se, sempre e no mínimo, ao tradutor, pois só assim o seu esforço valerá a pena. 